\title{
Messire Gilles de Chin, natif de Tournesis, Anne-Marie Liétard-Rouzé (éd.)
}

\section{Anne Schoysman}

\section{(2) OpenEdition}

1 Journals

\section{Édition électronique}

URL : http://journals.openedition.org/studifrancesi/5542

DOI : 10.4000/studifrancesi.5542

ISSN : 2427-5856

Éditeur

Rosenberg \& Sellier

\section{Édition imprimée}

Date de publication : 1 septembre 2011

Pagination : 389

ISSN : 0039-2944

\section{Référence électronique}

Anne Schoysman, «Messire Gilles de Chin, natif de Tournesis, Anne-Marie Liétard-Rouzé (éd.) », Studi

Francesi [En ligne], 164 (LV | II) | 2011, mis en ligne le 30 novembre 2015, consulté le 08 janvier 2021. URL : http://journals.openedition.org/studifrancesi/5542; DOI : https://doi.org/10.4000/studifrancesi. 5542

Ce document a été généré automatiquement le 8 janvier 2021.

\section{(c)}

Studi Francesi è distribuita con Licenza Creative Commons Attribuzione - Non commerciale - Non opere derivate 4.0 Internazionale. 


\section{Messire Gilles de Chin, natif de Tournesis, Anne-Marie Liétard-Rouzé (éd.)}

Anne Schoysman

\section{RÉFÉRENCE}

Messire Gilles de Chin, natif de Tournesis, Anne-Marie LIÉTARD-RouZÉ (éd.), Villeneuve d'Ascq, Presses Universitaires du Septentrion, 2010 («Textes et perspectives. Bibliothèque des Seigneurs du Nord»), 235 pp. [Sur CD version numérique de Messire de Chin, ms. God 50, BM de Lille].

1 La version anonyme en prose de Gilles de Chin est éditée ici pour la première fois d'après le ms. conservé à Lille, Bibliothèque Municipale, Godefroy 50. Présent déjà dans l'inventaire de 1467 de la Bibliothèque de Bourgogne, ce ms. porte les armes de Jean de Wavrin, bibliophile connu pour les ouvrages sur papier réalisés dans son atelier de Lille, et illustrés par les dessins aquarellés du «maître de Wavrin». Il comprend, outre Gilles de Chin, le Livre des Amours du Chastellain de Coucy et de la Dame de Fayel (éd. A. Petit et F. Suard, 1994; A.M. Babbi, 1994); d'après l'éditrice, il aurait été confectionné entre 1464 et 1467. Nous ne connaissons du Gilles de Chin en prose qu'un seul autre ms.: Bruxelles, KBR 10237 (éd. R. Chalon, 1837 et L.P. Cormier, 1954). Ce dernier comporte un prologue initial biffé, avec dédicace au bibliophile Jean de Créquy, dont ne fait plus mention le prologue réécrit; le ms., où interviennent trois mains et où des rubriques et des noms propres ont été introduits successivement sur des blancs, est un exemplaire typique de compilation d'atelier, et c'est sans aucun doute d'après celui-ci que le ms. de Lille a été copié pour Jean de Wavrin. Le Gilles de Chin en prose remanie un texte en vers dont ne nous est conservée qu'une copie de 1571 (Paris, Arsenal, ms. 3140: éd. Baron de Reiffenberg, 1847 et éd. E.-B. Place, 1941): copie vraisemblablement fidèle du poème de Gautier de Tournai (1230-1240), qui déclare reprendre l'histoire de Gilles de Chin de Gautier le Cordier (entre 1163 et 1175), quoique, d'après Langlois, ces deux noms se 
réfèrent à un seul et même personnage (cf. A. Henry, Gilles de Chin, dans Dictionnaire des Lettres françaises - Le Moyen Age, 1992). Gilles de Chin (fin XI ${ }^{\mathrm{e}}$ ou début XII ${ }^{\mathrm{e}} \mathrm{s} .-12$ août 1137), seigneur de Berlaimont et de Wasmes, fut proche de Baudouin IV, comte de Hainaut. L'histoire de ses prouesses et de son voyage en Palestine, considérée comme le premier roman historico-biographique, trouve son origine dans le milieu monastique hainuyer, en particulier l'abbaye de Saint-Ghislain (région de Tournai), très avantagée par les descendants de Gilles de Chin.

2 L'éditrice fournit en introduction une notice sur chacun des manuscrits, quelques informations sur les sources historiques et littéraires du poème (sources étudiées ailleurs par A. Petit, Les réminiscences littéraires dans le G. de Ch. en vers et en prose, dans Mettre en prose aux XIV -XVI ${ }^{e}$ s., M. Colombo-Timelli et alii éd., Turnhout, Brepols, 2010; cfr. SF 163, pp. 152-154), et un résumé du texte, avant de s'arrêter sur les techniques de mise en prose, pour l'étude desquelles nous n'avons toutefois pas de preuves que le remaniement se base précisément sur le texte copié dans le ms. de l'Arsenal. Si la clarification de la narration par l'usage de rubriques et de formules de transition et une certaine liberté dans le traitement des dialogues sont typiques des dérimages $\mathrm{du} \mathrm{Xv}^{\mathrm{e}} \mathrm{s}$., il est intéressant de remarquer que le prosateur tend ici à éliminer les réminiscences antiques de Gautier de Tournai pour privilégier l'Eneas ou Chrétien de Troyes (épisode $\mathrm{du}$ lion reconnaissant); surtout, il situe très concrètement son héros dans la réalité historique du Hainaut, développant ses «enfances», substituant Nassau à Duras, détaillant la géographie et les notations sur la vie courante. L'éditrice montre très clairement que cet exemple de fleur de chevalerie hainuyère vise à la fois à exalter la noblesse du Hainaut et à flatter la politique ducale. Une bibliographie générale des textes cités dans l'introduction aurait été souhaitable.

3 Une description synthétique de la langue du ms. God. 50 de Lille relève des faits syntaxiques qui sont tous courants en moyen français, et met en évidence ses traits picards. L'éditrice soulève la question (p. 21) de la comparaison avec la langue du ms. de Bruxelles, KBR 10237, dont un choix de variantes (pp. 193-197) nous donne une idée: il est intéressant de relever la fluctuation des graphies, notamment dans l'usage régional des phonèmes morphologiques, du copiste du ms. de Lille par rapport au copiste de Bruxelles, pourtant tout aussi picardisant. On regrette que ne soient pas explicités les critères de modernisation du texte dans la transcription, qui est fiable. Un index des noms propres et un glossaire suffisant (mais non analytique) clôturent cette édition qui permet désormais de lire le texte du premier roman biographique de la littérature française dans le texte de la belle copie exécutée d'après la «minute» du ms. de Bruxelles. Un $\mathrm{CD}$ joint au volume offre une très bonne reproduction en couleurs du texte de Gilles de Chin dans le ms. Lille, God. 50 (ainsi que des feuillets initiaux du ms., comprenant des indications de Godefroy, la table du premier texte, le Chastellain de Coucy, et les tout derniers ff. du ms.), permettant de consulter le ms. et d'apprécier le trait vif et essentiel des miniatures à l'aquarelle du «maître de Wavrin». 